\title{
Trigeminal trophic syndrome in a child - An unusual case report from Syria
}

\author{
Heba Fawal ${ }^{1}$, Zuheir Al-Shehabi ${ }^{2}$, Lina Soufi ${ }^{1}$
}

${ }^{1}$ Department of Dermatology, National Hospital, Lattakia, Syria, ${ }^{2}$ Faculty of Medicine, Tishreen Univesity, Lattakia, Syria

Corresponding author: Heba Fawal, MD, E-mail: fawalheba6@gmail.com

\begin{abstract}
The trigeminal trophic syndrome (TTS) is a rare form of cutaneous ulceration characterized by anesthesia, paresthesia and a secondary persistent facial ulceration. It is uncommon in children. However, we report an unusual case of TTS in a 5-year-old child with Moebius syndrome, extending over the right nostril and then the other nostril was infected. The diagnosis of TTS was based on clinical history, tissue biopsy and serologic evaluation. The ulcer was treated with multiple antibiotics with no improvement. We describe this case because of very few pediatric cases of TTS published in the past, and to increase the awareness of this syndrome among dermatologists.
\end{abstract}

Key words: Trigeminal trophic syndrome; Moebius syndrome

\section{INTRODUCTION}

The trigeminal trophic syndrome (TTS) is a rare condition resulting from peripheral or central injury to the trigeminal system. The syndrome consists of a triad of loss of sens, paresthesia, and a secondary facial ulceration that can be persistent or recurrent [1].

It was first described as a cutaneous ulceration in the trigeminal dermatome by Wallenberg in 1901 and later by Loveman in 1933 [2]. It is uncommon in children. However, we report an unusual case of TTS in 5 yearold child with Moebius syndrome.

\section{CASE REPORT}

A five year-old girl complained for a one year of a nonhealing painful progressive ulcer over the right nostril and then the other nostril was infected. She had Moebuis syndrome and had a wide range of characteristic clinical expressions such as mask-like facies, strabismus, sever hypotonia, high palate, limited mouth closing, developmental delay, limb anomalies (clubfoot) and hypoplastic right pectoral muscle. The ulcers were painful located on the ala nasi, extending medially into the nasal septum, superiorly over the skin of the nose. Their margins were clearly delineated (Fig. 1).

There were no vesicles around the ulcer or anywhere over the face. Her vitals and other systemic examination revealed no abnormality. Tzanck smear from the ulcer showed neutrophils and there were no acantholytic or multinucleate giant cell. Tests for tuberculosis and syphilis and lieshmaniasis and deep fungal infections were nonreactive. The hepatitis B, C and human immunodeficiency virus antibodies were negative. Her blood glucose, renal, and urine examination were within normal range, but there was a slight increase in liver tests LDH, CRP and ESR. Electrocardiography (ECG) and chest radiography, computed tomography (CT) scan, and magnetic resonance imaging (MRI) of the brain all were normal. It was considered a septic ulcer and was frequently treated with antibiotics based on antimicrobial sensitivity testing, which showed positive staphylococcus aureus and did not improve.

The biopsies were performed under general anesthesia by an (ENT) specialist from the nasal septum ulcer

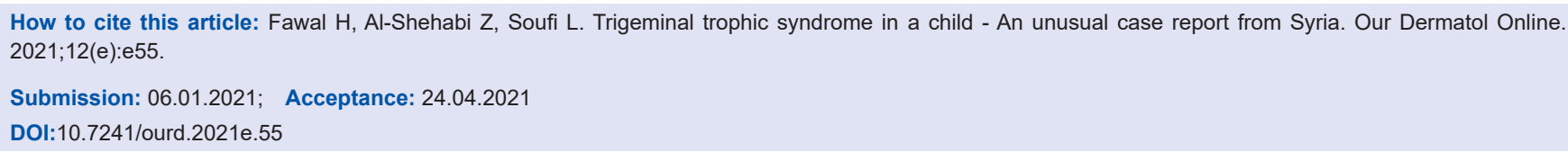


and the cartilage of nasal septum , and the histology shows chronic ulceration and necrosis with minimal inflammatory infiltrate and no giant cells or granuloma or cellular atypism (Fig. 2).

TTS was diagnosed and the ulcer was treated with multiple antibiotics (Bactrim), Amitriptyline and topical antiseptic. Parents were advised to monitor their child to avoid scratching or rubbing the ulceration site, the ulceration developed to collapse of the cartilaginous bridge of the nose (Fig. 3).

\section{DISCUSSION}

The trigeminal trophic syndrome is an unilateral, frequently crescent-shaped neurotrophic ulceration of the face. The majority of cases of trigeminal trophic syndrome are associated with a history of stroke or trigeminal nerve ablation. The appearance of the ulcers resembles other disease entities such as granulomatous disease, neoplasm, vasculitis, infections and factitial

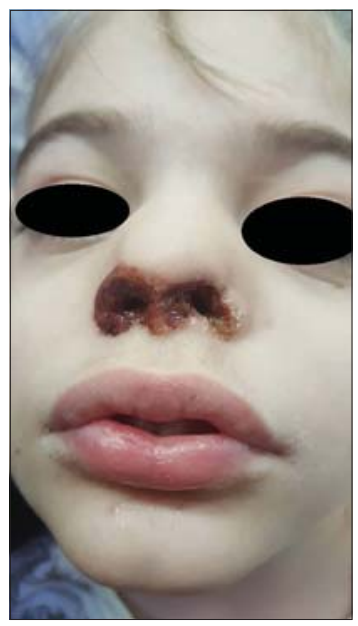

Figure 1: Clinical characteristics of the patient with Moebius syndrome (strabismus, mask-like facies, limited mouth closing), extensive nasal ulceration and trophic changes of the skin are clinical features of the trigeminal trophic syndrome.

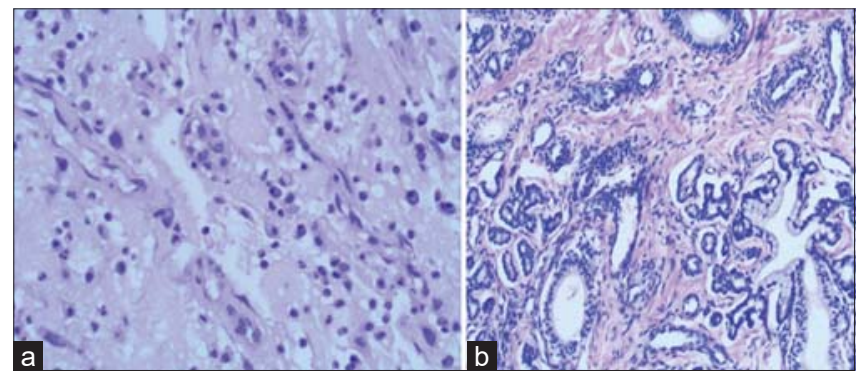

Figure 2: The histology shows: (a) chronic ulceration with minimal inflammatory infiltrate and no giant cells or granuloma (H\&Ex40). (b) Proliferation of thin wall blood vessels (H\&E x 100). dermatitis [4]. Most commonly seen in female than and more often in adults [3]. But in this case it occured to a child with neurological problems. TTS presents following certain conditions and diseases like trigeminal nerve ablation, Wallenberg syndrome (stroke/vascular insufficiency), tumors, postencephalitic sequelae, trauma, craniotomy, amyloid deposits in the CNS and trigeminal nerve, herpes zoster, herpes simplex, syphilis and neurological complications from birth, or it can be idiopathic. The biopsy is non-specific and insufficient for a diagnosis, it can help excluding other differential diagnoses $[3,4]$.

The management of TTS is often difficult as in our case. It involves neurologic evaluation, pain management for control of paraesthesia, psychological monitoring, medical treatment, and surgical repair [3]. And in some cases we need to protective devices to cover the wound as well as the hands/fingers of the patient. Therapeutic options reported in the literature include, diazepam, amitriptyline, chlorpromazine, carbamazepine, acyclovir, intralesional triamcinolone acetonide and surgical repair $[3,4]$. Some cases have been treated with Negative Pressure Wound Therapy with satisfying results [5].

The trigeminal ulcer is a rare complication of Moebius syndrome, but we should expect it in these patients and treat it correctly [6]. We have had difficulty in dealing with our patient because she suffers from a degree of mental retardation, which has aggravated the situation in terms of mechanical irritation and frequent ulcers rubbing.

We describe this case because of very few pediatric cases of TTS published in the past $[7,8]$, and to increase the awareness of this syndrome among dermatologists.

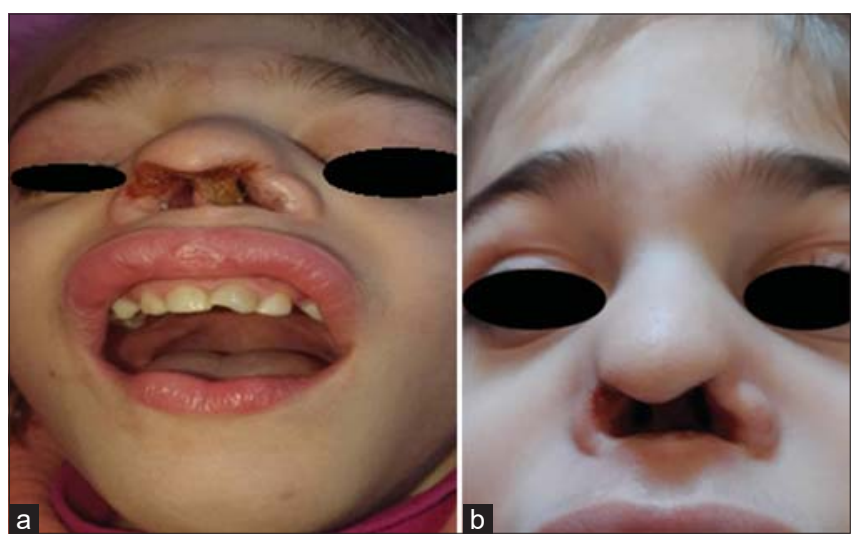

Figure 3: The development of the ulcer within 6 months, (a) before the treatment, (b) after treatment with Amitriptyline and Bactrim, the ulceration did not heal. (The eyes were not covered to show the strabismus). 


\section{CONCLUSION}

Trigeminal trophic syndrome is rare. However, the diagnosis of TTS should be suspected when there is an unilateral facial ulceration, especially involving the ala nasi associated with sensory impairment. More awareness, attention and early treatment will prevent major mutilation.

\section{Consent}

The examination of the patient was conducted according to the principles of the Declaration of Helsinki.

The authors certify that they have obtained all appropriate patient consent forms, in which the patients gave their consent for images and other clinical information to be included in the journal. The patients understand that their names and initials will not be published and due effort will be made to conceal their identity, but that anonymity cannot be guaranteed.

\section{REFERENCE}

1. Mishra SN, Nayak CS, Deshpande DJ, Pereira RR. Trigeminal trophic syndrome: A rare entity. Indian J Dermatol Venereol Leprol.
2011;77:729.

2. Shumway NK, Cole E, Fernandez KH. Neurocutaneous disease: Neurocutaneous dysesthesias. J Am Acad Dermatol. 2016;74:21528;quiz 229-30.

3. Khan AU, Khachemoune A. Trigeminal trophic syndrome: an updated review. Int J Dermatol. 2019;58:530-7.

4. Cardoso JC, Cokelaere K, Maertens M, Karim N, Jong TJ, Calonje E. When nonspecific histology can be a clue to the diagnosis: three cases of trigeminal trophic syndrome. Clin Exp Dermatol. 2014;39:596-9.

5. Sawada T, Asai J, Nomiyama T, Masuda K, Takenaka H, Katoh N. Trigeminal trophic syndrome: report of a case and review of the published work. J Dermatol. 2014;41:525-8.

6. Budić I, Šurdilović D, Slavković A, Marjanović V, Stević M, Simić D. Moebius syndrome: challenges of airway management. Acta Clin Croat. 2016;55 Suppl 1:94-7.

7. Dhawan AK, Bisherwal K, Grover C. Post herpes zoster trigeminal trophic syndrome in a child. Indian J Dermatol. 2015;60:414-5.

8. Caccavale S, Caccavale T, La Montagna M. Post herpes zoster trigeminal trophic syndrome in a child: an example of immunocompromised district. Indian J Dermatol. 2016;61:124.

Copyright by Heba Fawal, et al. This is an open-access article distributed under the terms of the Creative Commons Attribution License, which permits unrestricted use, distribution, and reproduction in any medium, provided the original author and source are credited.

Source of Support: Nil, Conflict of Interest: None declared. 